\title{
Una polémica sobre la revolución y la rebelión en el anarquismo gaditano.
}

\section{MARCOS JOSE CORREA LOPEZ}

Es por todos bien sabido la fundamental importancia que el anarquismo ha tenido históricamente en la configuración de los movimientos sociales gaditanos; del mismo modo, es de dominio público la multitud de formas y corrientes que han existido en el interior de la ideología libertaria. Fenómeno favorecido y posibilitado por su misma razón de ser original: el negar la existencia de cualquier autoridad, poder o dogma que se deba imponer. Esto es lo que ha facilitado que pudiesen existir, reclamando todas para sí su nombre, una gran diversidad de corrientes y tendencias anarquistas, a veces incluso radicalmente enfrentadas. Sobre una de ellas vamos a fijar ahora nuestra atención: aquella que recoge el pensamiento de dos figuras sumamente singulares en el mundo de la filosofía, concretamente alemana, y que en la provincia de Cádiz estuvo representada, materializada podríamos escribir, por un periódico publicado en La Línea, inscrito en lo que, en ocasiones, se ha venido en llamar la vertiente individualista del movimiento.

A través de este órgano de prensa de un grupo de revolucionarios (¿o deberíamos decir rebeldes?) de la provincia de Cádiz, nos acercaremos al, posiblemente, caso más curioso de desviación teórica en el movimiento obrero. Nos estamos refiriendo a una corriente que se aparta concretamente de la norma, llegando al extremo de negar cualquier validez a la actuación de las masas, de forma que, de un plumazo, destroza el principio democrático, razón por la que hemos traído tal asunto a este foro. Nos estamos refiriendo a la parte del movimiento ácrata que, en los años finales del siglo XIX y comienzos del XX se inclinó por mostrar su respaldo al pensamiento sustentado, fundamentalmente, por Friedrich Nietzsche y Max Stirner ${ }^{1}$, y que se conoce normal-

(1) Respecto a Max Stirner, diremos que es el seudónimo de Kaspar Schmidt, cuya obra principal es El Unico y su propiedad, publicado por primera vez en Berlín en 1845. Es fácilmente accesible en castellano gracias al textopublicado en Horowitz, I.L., Alianza, Madrid, 1982, pp.342-366. Sobre la obra de F. Nietzsche creemos innecesaria cualquier explicación. 
mente como anarquismo nietzschano, representado en la provincia por el periódico El Anticristo ${ }^{2}$. A lo largo de sus páginas podemos seguir la polémica que se entabla entre sus valedores y los partidarios del anarquismo tradicional, de masas.

La raíz del enfrentamiento arranca de los orígenes mismos de los movimientos sociales, de su fundamento utópico. Como dice Carr, y retrotrayéndonos a sus principios más lejanos, la utopía (y cualquier movimiento que se dispone a transformar el mundo tiene una) cristiana * tenía un rasgo distintivo propio: no pretendía el triunfo definitivo del rico y del poderoso, sino del pobre, del humilde y del débil..., y su adopación "como religión oficial de la civilización occidental perpetuó y legitimó esos elementos utópicos en el pensamiento occidental*.

La Ilustración consiguió *el maridaje entre la Utopía y el Culto a la Razón. Y de ahí, con el paso al siglo XIX sla tradición utópica... concebía mayormente el progreso en términos morales como el triunfo de la virtud y el remoldeamiento de la naturaleza humana ${ }^{3}$. Estos son los principios formadores, según Carr, de todos los socialismos, incluido el bolchevique; únicamente que "los marxistas sustituyeron la idealización de la naturaleza humana elemental y salvaje, que había sido desde Rousseau el distintivo común entre los utopistas, por la idealización del proletariado ${ }^{4}$. Entre estos dos extremos últimos, entrambos polos, y en multitud de posturas intermedias se desenvolvió el movimiento anarquista en el aspecto teórico. Sin embargo, precisamente en contra de ese punto fundamental y básico en todas las teorías revolucionarias (e incluso evolucionistas), se yergue el anarquismo de inspiración nietzscheana.

Los puntos comunes y de divergencia que puedan existir con el anarquismo, que aquí llamaremos tradicional para distinguir fácilmente, los iremos ilustrando precisamente a través de ejemplos del periódico que vamos a estudiar, y que, a pesar de ser claramente partidario, siguiendo la sana costumbre de la prensa ácrata española, acogía también en sus páginas artículos de aquellos que eran sus impuganadores. Para esto vamos a seguir la exposición que del asunto realiza Alvarez Junco,

(2) Nos estamos refiriendo a El Anticristo, subtitulado :Periódico anarquista. Queremos agradecer a D. Alberto Sanz Trelles el habernos facilitado los ejemplares de este periódico, conservados en el I.I.S.G. de Amsterdam. Tenemos que hacer una aclaración previa: en contra de lo que aparece en el libro de Alvarez Junco, J., La ideología política del anarquismo español (1868-1910), Siglo XXI, Madrid, 1976, este periódico se publica efectivamente en La Línea y no en Algeciras, como equivocadamente indica, lugar donde sí se efectuaba la tirada, por carecer la ciudad linense de imprenta entonces, tal y como se indica en el propio rotativo, No1, p.4.

(3) Carr, E.H., 1917. Antes y después, Sarpe, Madrid, 1985, pp.85-86.

(4) Ibidem., p.88. 
quien, hasta este momento, ha sido prácticamente el único que le ha prestado atención a la materia que aquí traemos a debates.

Comenzando por los aspectos en que, según Alvarez Junco, existe convergencia entre el anarquismo entendido en su versión normal, tradicional, y el movimiento anarco-nietzschenao, señala, en primer lugar, el individualismo y la libertad; "el individuo es, en principio, la única realidad existente. ${ }^{6}$. Tal parece deducirse del siguiente texto de Anselmo Lorenzo, quien no tiene, desde luego, nada en común, respecto al individualismo, con Nietzsche:

¿'Soy soberano? No cabe, pues, sobre mí otra soberanía ni cabe concebirla. Admitida, por lo tanto, la soberanía individual, ¿cómo admitir la colectiva??

$\mathrm{Y}$, desde luego, el individuo es la base, precisamente, de toda la construcción anarco-nietzscheana. Clarísimo esto en el caso de Stirner, para quien eel ser humano es la única cosa de lo que tenemos cierto conocimiento, y cada individuo es único. Es esta indiviualidad lo que cada hombre debe cultivar ${ }^{8}$.

En el mismo sentido se manifiestan los seguidores gaditanos de estos autores: "para nosotros no hay más realidad que nosotros mismos; y el mundo que nos rodea es un atributo nuestro o el campo de nuestra actividad al cual no reconocemos límite ni valla". Al igual de lo que ocurre en este fragmento, en el que se trata de impulsar *á los humanos hacia los ilimitados horizontes de la autonomía individual, proclamando al individuo como único valor real y positivo ${ }^{10}$.

Sin embargo, las cosas varían cuando nos centramos en el asunto de la libertad, que es básico y fundamental en la comprensión del anarquismo. De hecho, para García Moriyón, el libertarismo sse diferencia de las

(5) A lvarez Junco, Op.Cit., Ver capítulo 6. Hemos de decir que, precisamente este périódi-co, es el único que prácticamente no utiliza en su estudio de aquellos que representaron a esta corriente en España. También se puede consultar Sobejano, G., Nietzsche en Esspaña, Gredos, Madrid, 1967, que se centra en el impacto que el pensador alemás tuvo entre los intelectuales y artistas españoles, pasando de largo por su repercusión en el movimiento obrero. Además Sanz Escartín, F., Nietzsche y el anarquismo intelectual en España, Madrid, 1898, es decir, cuando aún no había sido prácticamente traducido y era conocido principalmente por referencias fragmentarias. Precisamente es en el año de 1898 en el que cifra Alvarez Junco el comienzo del acercamiento de los intelectuales a Nietzsche y al movimiento obrero, Op.Cit., p.148.

(6) Ibidem., p. 152.

(7) Citado en íbidem., p.19.

(8) Woodcock, G. El anarquismo, Ariel, Barcelona, 1979. p.95.

(9) El Anticristo, sHacia las Cumbres., firmado por la Redacción, №1, p.1. No nos cabe duda de que tras esa firma se esconde Salvador Rodríguez, que es quien se encarga de la correspondencia y rubrica varios otros artículos de cariz claramente nietzscheano.

(10) Ibidem., :Puntualizando. Individualismo y comunismo, Salvador Rodríguez, №2, p.1. 
demás corrientes socialistas por su especial énfasis en la crítica al estado y por una defensa radical de la libertad...11. Las referencias, en este caso más bien se refieren a lo opuesto: -...todo lo que sea anular la individualidad, es proclamar la esclavitud. Pero la libertad es un concepto extraño a los autores de los artículos de nuestro periódico; y en esto no se alejan, sino más bien todo lo contrario, de lo expuesto por sus inspiradores, dado que solamente soy libre de lo que estoy exento... Ser libre es algo que no puedo querer realmente, porque yo no puedo serlo, no puedo crearlo. Sólo puedo desearlo y aspirar a ello ya que no es más que un ideal, una quimera... Pero yo me sigo perteneciendo. Esta es la opinión de Stirner. Por tanto, para él la libertad es superada por la individualidad ("propiedad", lo que yo controlo), ya que sla misma naturaleza de la vida hace de la libertad absoluta un imposible, ${ }^{12}$.

Pero aún más lejos está Niezsche del concepto y el valor que tiene normalmente en el anarquismo la libertad, porque para él eel tipo supremo'de hombres libres habría que buscarlos alli donde constantemente se supera la resistencia suprema: a dos pasos de la tiranía, en los umbrales del peligro de la esclavitud.13.

Para Alvarez Junco, el siguiente punto en el que coinciden las dos escuelas que estamos estudiando, se centra en tla defensa de las exigencias de los instintos "vitales" frente a los convencionalismos sociales. ${ }^{14}$. Está bastante claro, creemos, para prácticamente todo el mundo, la decisiva importancia en la configuración de la moral anarquista que tiene el vitalismo, asunto expuesto por el mișmo Alvarez, donde citando a Mella escribe que "vencer las pasiones es vencer a la naturaleza., lo que ssupone luchar contra la causa de nuestra vida. ¿Por qué ha de ser inmoral lo que el hombre siente? ${ }^{15}$.

Los anarquistas nietzscheanos, ciertamente, se expresarán en términos bastante parecidos; además, reprueban a los religiosos porque ‘anulan su personalidad, se hacen místicos, aborrecen la vida, sus encantos, sus goces, por glorificar aquel fantasma que sus decadentes cerebros se han forjado, por veneración a cualquier efigie. ${ }^{16}$. En oposición a esto que entienden por visión religiosa, un autor afirma, samo la vida, la vida exhuberante [sic.] y fecunda. ${ }^{17}$.

(11) García Moriyón, F., Del Socialismo utópico al anarquismo, Cincel, Madrid, 1985, p.18.

(12) Woodcock, Op.Cit., p.96.

(13) Nietzsche, F., Crepúsculo de los ídolos, Alianza, Madrid, 1981, p.115.

(14) Alvarez Junco, Op.Cit., p.153.

(15) Ibidem., p.121.

(16) El Anticristo, Individualismo y comunismo., citado.

(17) Ibidem., .La Vida., S. Rodríguez, N², p.2. 
Todo esto no viene sino a reflejar el fuerte vitalismo que desprende la obra de Nietzsche. Pero, ¿vitalismo en qué sentido? ¿Qué significa la vida para Nietzsche; qué es? La respuesta no aparece nada clara ${ }^{18}$. En todo caso, podríamos decir, como nos indican estos ejemplos, que la vida es lucha: -Venimos a luchar. La lucha es vida ${ }^{29}$. En la lucha busco la vida, hembra fecunda y exhuberante [sic.], preñada de sensaciones y peripecias ${ }^{20}$.

Lo que acabamos de ver nos lleva a aquello que Alvarez Junco considera el tercer punto de contacto, de coincidencia, entre ambas corrientes de pensamiento: ‘la exaltación de la fuerza, de la acción, de la lucha y la rebeldía, frente a la vulgaridad, moderación, palabrería, pasividad y conformismo reinantes. ${ }^{21}$. Y para corroborar el apoyo a estas mismas ideas por el anarquismo tradicional, se fundamenta en fragmentos de Ricardo Mella, quien no puede ser precisamente tenido por uno de los autores más incendiarios o partidarios de la violencia gratuita, como confirma su aseveración de que "por la violencia se han afirmado y constituido todos los poderes y todas las tiranías. La violencia en sí misma es odiosa ${ }^{22}$. Sin embargo, respaldando la opinión mencionada de Alvarez Junco, también llega Mella a decir, en el momento apropiado, .habréis de apelar a la fuerza, porque la fuerza sometidos os tiene.... ${ }^{23} .0$, incluso: "No os asombren nuestros cantos al exterminio de la iniquidad. Destruir es nuestra primera obra. La edificación vendrá enseguida, inmediatamente. Llama ya a nuestras puertas. ${ }^{24}$.

Sin embargo, esta última cita nos introduce un elemento de falla; de fractura en la continuidad de ambas doctrinas, porque la violencia del anarcocomunismo y del anarcocolectivismo tiene un fin muy concretamente determinado y claro, que se corresponde con una visión racionalista del devenir humano. El mismo Alvarez junco se encargará de recordar esto más adelante y de ponerlo en oposición frente a la crítica nietzscheana a la razón, la ciencia y el progreso ${ }^{25}$.

Pero resulta que, a partir de aquí, debemos entonces de comenzar a plantearnos la cuestión sobre el origen y el fin de esa lucha que es la vida, el motivo de emplear la fuerza y la rebeldía y, como veremos, 'las

(18) Para un acercamiento somero puede consultarse la breve introducción que se encuentra en Hirschberger, J., Historia de la Filosofia, Herder, Barcelona, 1979, pp.328-346.

(19) El Anticristo, .Venimos..., S. Rodríguez, №1, p.2.

(20) El Anticristo, :La vida., citado

(21) Alvarez Junco, Op. Cit., p. 154

(22) Ver Segarra, A., Federico Urales y Ricardo Mella, teóricos del anarquismo español, Anagram, Barcelona, 1977, p. 82.

(23) Ibidem., p. 79.

(24) Ibidem., p. 67.

(25) Alvarez Junco, Op. Cit.,p.161. 
diferencias a partir de aquí serán tan grandes, tan abismales y tan abisales, que esos puntos comunes existentes que hasta ahora han sido mencionados, nos parecerán tan débilies y tan poco llamativos, que vienen a representar lo mismo que si afirmásemos que el bolchevismo y el fascismo tienen en común el convencimiento de la nececidad de la violencia y de un Estado fuerte. Es decir, algo absolutamente anecdótico en relación con su auténtica trascendencia.

Hemós hablado de rebelión hace un momento, y a este concepto acudimos ahora, a través de Stimer, para seguir profundizando en este asunto:

*No debe considerarse a la revolución y a la rebelión como sinónimos. La primera consiste en un trastueque de las condiciones, de la condición establecida, o status, el estado o la sociedad, y es por lo tanto un acto político o social. La segunda tiene, ciertamente, como inevitable consecuencia una transformación de las circunstancias, sin embargo, no arranca de ahí, sino del descontento de los hombres consigo mismos. No es un alzamiento armado, sino un alzamiento de indiviuos, un levantamiento sin mirar las consecuencias que de él pueden derivarse. La revolución apunta a nuevos arreglos; la rebelión nos libera de estar sujetos a arreglos, nos lleva a arreglarnos a nosotros mismos y no pone ninguna esperanza deslumbrante en las instituciones. No es una lucha contra lo establecido, ya que, si ésta prospera, lo establecido muere por sî mismo... Como mi objetivo no es derrocar ningún orden establecido, sino mi elevación sobre él, mi propósito y mis acciones no son políticos ni sociales, sino egoístas. ${ }^{26}$.

De acuerdo con este párrafo, resulta entonces que la insurrección, la lucha propuesta por el anarquismo tradicional es una revolución y no una rebelión. Su fin es actuar en la sociedad, alterar completamente, estructuralmente, las bases de la sociedad presente y proceder más tarde a la edificación de lo nuevo, como algo más arriba hemos visto decir a Mella: .la edificación vendrá enseguida. Nos hallamos situados, entonces, ante la realidad de que el anarquismo propugna una revolución política, según Max Stirner. En efecto, el anarquismo es un proyecto colectivo de socialismo, del que Mella afirma que los aprincipios fundamentales son los siguientes:

$1^{\circ}$ - Todos los hombres tienen necesidad de desarrollo físico y mental en grado y forma indeterminada.

$2^{2}$ - Todos los hombres tienen el derecho de satisfacer libremente esta necesidad de desarrollo.

$3^{2}$ - Todos los hombres pueden satisfacerla por medio de la cooperación o comunidad voluntaria ${ }^{27}$.

(26) Woodcock, Op.Cit., pp.99-100.

(27) Mella, R., Ideario, Producciones Editoriales, Barcelona, 1978, p.24. 
Proyecto colectivo que para llegar a buen fin debe, lógicamente, de alterar las condiciones sociales, políticas en definitiva, motivo por el que el socialismo anarquista se enfrenta entonces al Estado, garante de la pervivencia de la presente situación. Otros distintos son los motivos que le llevan a enfrentarse a Stirner con la realidad estatal y a ser, por tanto, un rebelde:

-Para el estado, es indispensable que nadie tenga una voluntad propia. Si alguien la tuviera, el estado se encargará de excluirle, encerrarle, o detenerle. Si la tuvieran todos, conseguirían destruir el estado. No puede concebirse el estado sin dominio y sin esclavitud; ya que el estado quiere ser señor de todo lo que abarca. A esta voluntad se la llama. la .voluntad del estado... Mi propia voluntad es el destructor del estado; por lo tanto el estado la estigmatiza como aautovoluntad. La propia voluntad y el estado son poderes en lucha a muerte, entre los cuales no es posible "paz eterna.22.

Es, por tanto, el motivo del enfrentamiento con las instituciones, con el Estado de los seguidores de las doctrinas de Stirner y Nietzsche el mantenimiento de su propia voluntad, el objetivo de su vida, que es lucha: el fin que perseguimos en la lucha es el de elevarnos el de desprendernos de todo lo que debilita nuestra voluntad ó entorpece nuestra acción, de adquirir más energía y más potencia, de barrer de la vida todo lo inútil y podrido...,29.

En lógica conclusión de todo esto, si cada uno lucha, aisladamente y por su cuenta, por mantener y fortalecer su propia voluntad, la vida en todos sus aspectos es una lucha encarnizada de fuerzas y opuestas individualidades que se disputan el predominio y que en la batalla desarrollan y desenvuelven sus aptitudes, pereciendo las formas inferiores é imperfectas para que triunfen y se perpetúen los fuertes y superiores. ${ }^{30}$.

Estamos ante una lucha por mantenerse, por sobrevivir, por imponerse, en definitiva, nos hallamos ante una lucha a muerte por el poder, tal y como se puede leer en el periódico, donde se encuentra la siguiente cita de Nietzsche: ¿ ¿ Qué es bueno? -Todo lo que aumenta en el hombre el sentimiento del poder, el poder mismo.

¿Qué es malo? - Todo lo que procede de la debilidad.

¿Qué es la dicha? - El sentimiento de que el poder se agranda - de que se vence una resistencia.

*No contentamiento, sino más poder; no virtud, sino valor ${ }^{31}$.

(28) Woodcock, Op.Cit., p.97.

(29) El Anticristo, ·Hacia las Cumbres., citado.

(30) Ibidem.

(31) Ibidem., .Rayos de luz., №1, p.2. 
Si nos encontramos, como parece tras estas palabras, ante una abierta guerra a muerte de todos contra todos, ¿dónde está el principio moral, dónde está el derecho? A èsta pregunta nos contesta la redacción del rotativo incluyendo un texto, en la misma sección que el anterior, pero en el número siguiente, de Stirner: "Cuando se habla de derecho hay una cuestión que se plantea siempre. :Quién o qué cosa nos da el derecho de hacer esto o aquello?* Respuesta: ‘iDios, el Amor, la Razón, la Humanidad, etc.!' iEh, no, amigo mío! Lo que te da ese derecho es tu fuerza, tu poder y nada más tu razón, por ejemplo, puede dártelo. ${ }^{32}$.

En esta lucha, la corriente de pensamiento que estudiamos tiene muy çlaro cual es el futuro que hallará cada uno: dependerá única y exclusivamente de sus fuerzas para imponerse a los demás. Por eso se afirma que el porvenir es de los fuertes; de los decididos, de los capacitados para la lucha. Y por esta selección natural é indestructible, es como vàn superándose las especies, aniquilando a los débiles. Y esas ansias son las que rebosan por mis juveniles poros. Me aguijoneo a mí mismo por sentir ansias de vencer, de influir en los demás. Por eso me acorazo con una firme y enérgica voluntad. No quiero renunciar á ella, no puedo. Ello implicaría la muerte, fea é infecunda, del impotente. ${ }^{33}$.

Tal coraza, la dureza del luchador nietzscheano, no debe perderse nunca según los redactores de nuestro periódico, porque si no deja de ser fuente de voluntad, de dureza y puede caerse en la preocupación por los demás, en vez de fijarse en el acracentamiento de la propia voluntad, es decir, lo que vulgarmente se conoce por "ser bueno", y ،hacer el bien á la sociedad, es, hacerse uno el mal, y hacer el propio bien para sí, es no hacer ni el bien ni el mal para con los demás. ${ }^{34}$.

Tenemos, por tanto, al individuo solo, erguido en medio de la tierra, él solo contra el mundo, sin deber ni depender en nada de nadie. ¿Es esto libertad? Ya vimos más arriba que ni Nietzsche ni Stirner se preocupan gran cosa por ese concepto, aunque sí, como hemos visto afirmar a éste último, la libertad es la aısencia, el no tener, en ese caso el individuo que está en la situación antes señalada es libre del todo, menos de su propiedad, de su individualidad.

Si ahora volvemos la vista hacia el anarquismo, tenemos que "la anarquía es secillamente la libertad total: la libertad de pensamiento, libertad de acción, libertad de contratación, basada en la más completa igualdad de condiciones humanas, tanto económicas como jurídicas, políticas y sociales. La libertad y la igualdad son dos afirmaciones funda-

(32) Ibidem., :Rayos de luz, No2, p.3.

(33) Ibidem., sEl vuelo del águila., F. Rodríguez Cabrera, №2, p.3.

(34) Ibidem., -La Vida., citado. 
mentales. (...) Consagrándose una y otra por el espontáneo funcionamiento de todos los individuos y los organismos mediante el pacto. ${ }^{35}$.

En contra de las luchas despiadadas por imponer la propia voluntad a otros; a los demás, por el poder en definitiva,el anarquismo ofrece el ideal de la solidaridad y de la igualdad como fundamentos de la auténtica libertad. Y precisamente las culpas de todos los males y fracasos sociales se los achaca a la presencia del egoismo:al intento de ciertos individuos por imponerse a otros, atacando la base fundamental de la otra filosofía: imponerse al otro, y esto recurriendo al racionalismo, tan caro a los anarquistas:

-...el análisis científico nos suministra la evidencia de la perfecta solidaridad y armonía que palpita en la vida de las células de los organismos y en todo el cosmos y vemos en las sociedades humanas las luchas del egoísmo y de la competencia desenfrenada y el despiadado pisoteamiento de multitudes..., ${ }^{36}$.

El egoísmo, por tanto, es el que se entromete en lo que debiera ser el normal, natural y armónico transcurrir de los días, inmersos dentro de la mayor de las solidaridades. Pero el egoísmo, con su real existencia y con su labor nefítica y contaminadora, no deja de ejercer: $\mathrm{Si}$ el ambiente no estuviese saturado de egoísmo, sería bueno y siendo bueno, sería feliz, haciendo felices a todos sus semejantes; pero como el ambiente social, es de puro egoísmo, el individuo no puede ser bueno y si lo es en la extensión completa del concepto altruista, es hombre irremisiblemente perdido, es un náufrago en la inmensidad de un mar proceloso y sin orillas.37.

Esto es así, repetimos, porque el ambiente está saturado de egoísmo, y el egoísmo, naturalmel te, en lógica consecuencia, actúa en la creación de privilegios exclusivos de los más fuertes, de los más preparados. Pero hay quien ve la "creación apocalíptica..." cómo se vislumbra perfilada en líneas de sangre y fuego en el horizonte visible de la sociedad actual, como presagio del total aniquilamiento del privilegio. Los horrores del presente nos llenan de consternación, nos hacen lanzar imprecaciones de ira; pero al mismo tiempo nos enardecen para con decisión perseverar en la lucha....38.

A la lucha no a favor de uno mismo, rebelde en sentido stirneriano, sino a la lucha, a la pelea en favor de un cambio en las condiciones sociales y polícas exteriores a nosotros: •Vemos en lontananza el Anticristo

(35) Mella, R. Forjando un mundo libre, Ed. La Piqueta, Madrid, 1978, p.33.

(36) El Anticristo, ·Hacia el porvenir., José Prat, №1, pp.2-3.

(37) Ibidem.

(38) Ibidem., En el Centro Obrero, L. de la Corza, №1, p.4, es un artículo en el que se narra una conferencia dada por March, precisamente bajo el título :Egoísmo y altruismo, quien también presenta un artículo, no precisamente nietzscheano en su contenido, en este número. 
devastador de un régimen caduco y moribundo, convirtiéndose en heraldo flaminio de una vida nueva, exhuberante [sic.], cuya necesidad se deja sentir cada día con mayor fuerza. ${ }^{39}$.

Un cambio de régimen, en definitiva, es a lo que aspira Vicente March, autor de estas líneas que, sin embargo y contradictoriamente, no dejan de tener, en cuanto a los términos utilizados, un claro y evidente regusto nietzscheano, con sus referencias al fuego, a la lucha y al Anticristo. Exactamente lo mismo se puede observar que ocurre en otros autores:

i iLa fuerza! Cantemos a la fuerza. Ella es la madre de todo lo creado...Cantemos al puñal, cantemos al revolver, cantemos a la bomba... ¿Que son armas de destrucción? Sí, pero destruyen el mal, destruyen la tiranía, destruyen lo que se opone a la práctica del bien; son las únicas que en estos tiempos han velado por la libertad, han contenido el brazo del verdugo, han contribuido a afianzar las conquistas progresivas... Cantemos a la fuerza, a la fuerza que mata para dar vida, que es a la vez destructora y creadora... Odiemos la fuerza que mata, que destruye, que asola, sin que su finalidad entrañe más que el egoísmo de los poderosos... Odiemos la guerra.40.

Hay, como se puede colegir de esto, entonces, una violencia que se considera legítima y otra que no. La segunda es la que nace del egoísmo de los poderosos", y la fuerza y la violencia válidas y justificadas son aquellas que se le oponen, que intentan eliminar la anterior "tiranía. Hemos ido viendo varias alusiones que se dirigían a señalar como origen de esta inaceptada situación actual el egoísmo del ambiente en que el hombre se desenvuelve. Esto a lo que nos estamos refiriendo, el ambiente social, es fundamental en el anarquismo para explicar el comportamiento singular de cada persona: :Todo individuo humano, sin excepción, no es sino un producto involuntario del medio social y natural. Cuatro son las causas de la inmoralidad del hombre: 1) la carencia de higiene e instrucción racionales; 2) la desigualdad en las condiciones económicas y sociales; 3) la ignorancia de las masas que emana naturalmente de su situación ; y 4) la consecuencia inevitable de esas circunstancias: la esclavitud *a1.

Esto es algo que los nietzschaneos no están, en modo alguno, dispuestos a admitir: el hecho de que la condición moral del individuo obedezca a la acción de causas exteriores: "Hay que apuntar el craso error que priva de creer que son las formas y relaciones sociales las únicas culpables de todos los males y desastres, sin conceder valor

(39) Ibidem., -El Anticristo, Vicente March, No1, p.3.

(40) Núñez Florencio, El Terrorismo anarquista, Siglo XXI, Madrid, 1983, p.217. Está tomado de un texto de El Rebelde, №9 (1904), titulado -Antimilitarismo.

(41) Bakunin, M., El sistema del anarquismo, Proyección, Buenos Aires, 1973, p.148. 
alguno al individuo, a quien juzgan un autómata modela do y movido por el medio ambiente como por un resorte, deduciendo pues, que no es al individuo, sino á la sociedad -fantasma tan ilusorio como la patria- a quien hay que reformar. ${ }^{42}$.

Exactamente lo mismo viene a decir su maestro, alcanzando en su razonamiento a identificar anarquismo y cristianismo: -Un instinto causal domina en él [el anarquista]: alguien tiene que ser culpable de que él se encuentre mal...Si yo soy un canaille, también tú deberías serlo: con esta lógica se hace la revolución. -El quejarse no sirve de nada en ningún caso: es algo que proviene de la debilidad. Atribuir el propio malestar a los demás o a sí mismo- lo primero lo hace el socialista, lo último, por ejemplo, el cristiano -no constituye diferencia ${ }^{43}$.

Esta identificación entre anarquismo y cristianismo es motivo principal de atención en nuestro periódico. Todas las aspiraciones y grandes conceptos clave (fruto de la herencia utópica racionalista) del anarquismo son duramente atacados desde las páginas del rotativo linense, porque toda idea, toda concepción que tienda a la anulación del yo, de la individualidad es idea muerta, por ser la antítesis de la vida. ${ }^{44}$.

Y abundan las ideas que apuntan a tener este preeminencia sobre la propia individualidad: "Hoy los anarquistas, así como los cristianos se unen por las ideas de Dios, Patria, Religión, éstos se unen por otras abstracciones no menos vacías de sentido, como, "Justicia", "Verdad", - Bienestar Común* y sacrificio por la Humanidad, resultando que a los fantasmas creados por el hombre en la noche de los tiempos, no han hecho más que cambiar de nombre y lugar. $\mathrm{Y}$ así vemos al hombre castradas sus energías, de su voluntad y entereza para desembarazarse de ese legado atávico ... ídolos antiguos. ${ }^{45}$.

En definitiva, toda las ideologías que tienen que ver con la mejora social, con el intento de alterar las condiciones en las que se desenvuelven todos los hombres, que tienen, por tanto, una raíz utópica, como veíamos al principio, opinan los nietzscheanos que no son diferenciables del cristianismo, adormidera de espíritus, en cuanto su preocupación se centra en aquellos que, solos, como individualidades singulares, son incapaces de imponerse en el contexto de la lucha por la vida. Por eso se arirma: “...con ayuda de una religión que ha estado a favor de y ha adulado los deseos más sublimes del animal de rebaño, se ha llegado a que nosotros mismos encontremos una expresión cada vez más visible

(42) El Anticristo, .Barriendo escombros., A. Herrero, №1, p.3.

(43) Nietzsche, Op.Cit., epigrafe -El cristiano y el anarquista., p.107.

(44) El Anticristo, .Individualismo y comunismo., citado.

(45) Ibidem. 
de esa moral en las instituciones políticas y sociales: el movimiento democrático constituye la herencia del movimiento cristiano. ${ }^{46}$.

Para concluir, creemos que se puede afirmar que esta corriente nietzscheana realmente no puede ser asimilable al anarquismo, en cuanto que, dada su repugnancia hacia la inmensa mayoría de la población y el desinterés que muestra por su regeneración es imposible catalogarlo como un socialismo, tronco fundamental, desgajado del pensamiento liberal ilustrado, del que el movimiento libertario nace. Por otra parte, no deja de ser interesante acercarse a esta escuela para estudiar su rechazo de cualquier tipo de "alegría" democrática, precisamente por el origen castrador y anulador de las voluntades que, según los nietzscheanos, tiene.

(46) Nietzsche, F., Más allá del bien y del mal, Alianza, Madrid, 1979, pp.133-134. 